\title{
Higher Muscle Content of Perilipin 5 and Endothelial Lipase Protein in Trained Than Untrained Middle-Aged Men
}

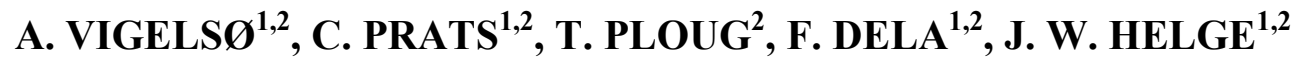 \\ ${ }^{1}$ Center for Healthy Aging, and ${ }^{2}$ Department of Biomedical Sciences, Faculty of Health Sciences, \\ University of Copenhagen, Copenhagen, Denmark
}

Received March 5, 2015

Accepted June 5, 2015

On-line October 8, 2015

\begin{abstract}
Summary
A high $\mathrm{VO}_{2}$ max in middle-age is related to high metabolic flexibility and lowered risk of metabolic diseases. However, the influence of a high $\mathrm{VO}_{2}$ max induced by years of regular training in middle-age on protein expression related to muscle metabolism is not well studied. This study measures key proteins involved in mitochondrial oxidation, glucose and lipid metabolism in skeletal muscle of trained and untrained middle-aged men. 16 middle-aged men, matched for lean body mass, were recruited into an endurance trained $(T R, n=8)$ or an untrained $(\mathrm{CON}, \mathrm{n}=8)$ group based on their $\mathrm{VO}_{2}$ max. A muscle biopsy was obtained from $m$. vastus lateralis and protein levels were analyzed by Western blotting. The TR had higher protein levels of mitochondrial complex III-V, endothelial lipase (EL) and perilipin 5 compared to the CON. Glycogen synthase $(P=0.05)$, perilipin 3 $(P=0.09)$ and ATGL $(P=0.09)$ tended to be higher in TR than CON, but there was no difference in AKT I/II, HKII, GLUT4 and LPL protein expression. Lastly, there was a positive correlation between plasma $\mathrm{HDL}$ and $\mathrm{EL}\left(\mathrm{R}^{2}=0.53, \mathrm{P}<0.01\right)$. In conclusion, a high $\mathrm{VO}_{2}$ max in middle-aged men was as expected is reflected in higher muscle oxidative capacity, but also in higher endothelial lipase and perilipin 5 expression and a borderline higher glycogen synthase protein expression, which may contribute to a higher metabolic flexibility.
\end{abstract}

\section{Key words}

Lipid metabolism - Glucose metabolism - Endurance training • Middle-aged men • Human skeletal muscle

\section{Corresponding author}

A. Vigelsø, Center for Healthy Aging, Department of Biomedical Sciences, Panum Institute, 12.4., Blegdamsvej 3, 2200 Copenhagen N, Denmark. E-mail: avhansen@sund.ku.dk

\section{Introduction}

Having a high aerobic capacity $\left(\mathrm{VO}_{2} \mathrm{max}\right)$ while we age contributes positively to muscle metabolic flexibility and decreases the age-related risk of developing metabolic diseases (Bonadonna et al. 1994, Kelley et al. 2002, Kelley and Mandarino 2000, Ritz et al. 1998, Storlien et al. 2004). At the muscular level a higher $\mathrm{VO}_{2} \mathrm{max}$ is reflected in higher mitochondrial oxidative capacity, which is due to both increased mitochondrial mass and increases in mitochondrial complexes (Gram et al. 2014). However, the molecular mechanisms that control and regulate glucose uptake as well as lipid uptake and storage and thus affects metabolic flexibility are only partly understood.

In regards to glucose metabolism, a high $\mathrm{VO}_{2} \mathrm{max}$ in both young (Dela 1996) and older men (Cox et al. 1999, Tonino 1989) is associated with an improved insulin-stimulated response and hence improved glucose metabolism. At the muscle level this has been coupled to increased protein levels of hexokinase II (Frosig et al. 2007), AKT I and II (Frosig et al. 2007), and GLUT4 (Cox et al. 1999, Dela et al. 1993, Hickner et al. 1997, Ren et al. 1994) in young individuals. But these proteins have, to our knowledge, not been analyzed together in the same study in middle-aged men before; such knowledge would provide information about the overall training induced differences in this age-group.

Fatty acid (FA) oxidation is improved by endurance training (Henriksson 1977, Hurley et al. 1986, Martin et al. 1993). At the muscular level this occurs through several adaptations. In FA uptake, endothelial lipase (EL) and lipoprotein lipase (LPL) are the primary 
lipases involved in hydrolysis of triglycerides in plasma lipoproteins (Griffon et al. 2006, McCoy et al. 2002). LPL has been shown to increase with training in young individuals (Lithell et al. 1979, Nikkila et al. 1978, Taskinen and Nikkila 1980), but less is known about EL. EL is not expressed in muscle cells but in the endothelial cells and macrophages (Annema and Tietge 2011) and there is no evidence for a specific functional role of EL in skeletal muscle. However, based on a study of fat cells from mice that lacked LPL, it was demonstrated that EL mediates an alternative pathway for FA uptake in adipose tissue (Kratky et al. 2005). We have previously reported that EL expression in human skeletal muscle was similar between untrained healthy middle aged men and age and lean body mass matched men with type 2 diabetes or impaired glucose tolerance (Vigelsø et al. 2013). Yet, it is not known if EL expression in the endothelial tissue of human skeletal muscle is influenced by a marked difference in $\mathrm{VO}_{2}$ max after years of regular training.

The intramuscular release of FA from the lipid droplets for oxidation are controlled by hormonesensitive lipase (HSL) and adipose triglyceride lipase (ATGL), which are regulated by the lipid droplet related proteins, perilipin 2, 3 and 5 (Bartz et al. 2007, Brasaemle et al. 2004). In young individuals training increases the protein expression of perilipin 2 (Shaw et al. 2012, Shepherd et al. 2013), perilipin 3 (Louche et al. 2013) and perilipin 5 (Peters et al. 2012, Shepherd et al. 2013) in skeletal muscle. Although the regulation of lipid droplet function and muscle lipid uptake has improved considerably in the latter years this knowledge has primarily been gained from studies of young individuals and thus little is known about the effect of age and the influence of training. It is thus interesting to investigate differences in the key proteins in lipid uptake and lipid droplet regulation in aged individuals that exhibit a marked difference in maximal oxygen uptake through exposure to life-long training.

Therefore, we studied the expression of proteins involved in glucose and lipid metabolism in skeletal muscle from middle-aged men having either a normal or a high $\mathrm{VO}_{2} \max$. We hypothesized that middle-aged men with a high $\mathrm{VO}_{2}$ max would have higher levels of the key proteins involved in glucose uptake and lipid uptake and storage compared to untrained middle-aged men.

\section{Material and Methods}

\section{Participants}

16 middle-aged men were recruited into two groups of either healthy sedentary controls $(\mathrm{CON}, \mathrm{n}=8)$ or endurance-trained participants $(\mathrm{TR}, \mathrm{n}=8)$. The groups were matched for age and LBM (Table 1). The participants in CON were not allowed to do regular exercise, whereas the TR group should perform regular endurance training (e.g. running or cycling). Furthermore, the participants in TR had all been performing regular endurance training for many years. Exclusion criteria were: prescribed medication, family history of type 2 diabetes, severe obesity or cardiovascular disease. Furthermore, the participants were instructed to refrain from alcohol, tobacco and strenuous exercise $48 \mathrm{~h}$ prior to the screening and experimental day. All participants received written and verbal information about the purpose and potential risks and complications of the experiment. Informed written consent was obtained before inclusion. The study was approved by the Copenhagen Ethics Committee (KF 01-091/02) and was carried out in accordance with the Declaration of Helsinki II.

Table 1. Group characteristics.

\begin{tabular}{|c|c|c|}
\hline & $\begin{array}{c}\text { Healthy } \\
\text { sedentary } \\
\text { controls } \\
(\mathrm{CON})\end{array}$ & $\begin{array}{c}\text { Endurance } \\
\text { trained } \\
\text { (TR) }\end{array}$ \\
\hline $\mathrm{N}$ & 8 & 8 \\
\hline${ }^{\#}$ Age (years) & $53 \pm 2$ & $51 \pm 2$ \\
\hline${ }^{\#}$ Weight (kg) & $93 \pm 3$ & $82 \pm 5^{*}$ \\
\hline${ }^{\#} B M I\left(\mathrm{~kg} \cdot \mathrm{m}^{-2}\right)$ & $29 \pm 1$ & $25 \pm 1^{*}$ \\
\hline${ }^{\#}$ Whole body fat (\%) & $26 \pm 1$ & $18 \pm 1^{*}$ \\
\hline${ }^{\#} L B M(\mathrm{~kg})$ & $65 \pm 2$ & $63 \pm 3$ \\
\hline $\begin{array}{l}{ }^{\#} \mathrm{VO}_{2} \max \\
\left(\mathrm{ml} \mathrm{O}_{2} \cdot \mathrm{kg} L B M^{-1} \cdot \mathrm{min}^{-1}\right)\end{array}$ & $43 \pm 2$ & $58 \pm 2^{*}$ \\
\hline $\begin{array}{l}{ }_{S S G I R} \\
\left(\mathrm{mg} \cdot[\mathrm{kg} \mathrm{LBM}]^{-1} \cdot \mathrm{min}^{-1}\right)\end{array}$ & $13 \pm 1$ & $18 \pm 1^{*}$ \\
\hline $\begin{array}{l}{ }^{*} \text { Glycogen } \\
\left(\text { nmol } \cdot \mathrm{mg}^{-1} \text { d.w.) }\right.\end{array}$ & $57 \pm 7$ & $107 \pm 11^{*}$ \\
\hline IMTG (nmol.mg ${ }^{-1}$ d.w.) & $33 \pm 9$ & $29 \pm 9$ \\
\hline
\end{tabular}

Data are means \pm SEM. BMI, Body mass index; LBM, Lean body mass; $\mathrm{VO}_{2}$ max, Peak oxygen uptake; ssGIR, steady state glucose infusion rate during the euglycemic-hyperinsulinemic clamp step 2. \# Data have previously been published (Skov-Jensen et al. 2007, Skovbro et al. 2008, Vigelsø et al. 2013). * P<0.05

The present project was part of a large study that focused on insulin sensitivity and lipid metabolism in patients with type 2 diabetes or matched participants with either impaired glucose tolerance, or sedentary or trained 
(Skov-Jensen et al. 2007, Skovbro et al. 2008, Vigelsø et al. 2013). In the present study, only muscle biopsies from the healthy, but sedentary control participants and the trained participants are studied to elucidate the effect of having a high $\mathrm{VO}_{2}$ max in middle-age on key proteins in lipid and glucose metabolism. Most of the descriptive data on these participants have been reported previously (Skov-Jensen et al. 2007, Skovbro et al. 2008, Vigelsø et al. 2013) and this is clearly referenced in the paper.

\section{Testing and experimental procedure}

The study consisted of a screening/test day and an experimental day, both performed after an overnight fast and separated by 4-7 days. On the first day, anthropometrical measures were obtained (body weight and height; body composition (dual-energy X-ray absorptiometry, DXA; DPX-IQ 240, Lunar, Madison, WI, USA)). Peak oxygen uptake, $\left(\mathrm{VO}_{2} \max \right)$ was determined using a graded exercise test on a semi-supine bike and oxygen consumption, was monitored on an online system (Oxycon Pro system, Jaeger, Hoechberg, Germany).

On the experimental day, muscle biopsies were obtained from $m$. vastus lateralis after $30 \mathrm{~min}$ of rest in the supine position using the Bergström muscle biopsy needle technique modified to include suction. The muscle tissue was frozen in liquid nitrogen within $10-15 \mathrm{~s}$ of sampling and stored at $-80{ }^{\circ} \mathrm{C}$ until further analysis. Thereafter, the participants underwent a two-step sequential euglycemic-hyperinsulinemic clamp, lasting 120 and 90 min for step 1 and 2, respectively. In step 1 and 2, an insulin infusion rate of 28 and $80 \mathrm{mU} \cdot \mathrm{m}^{-2} \cdot \mathrm{min}^{-1}$ were used, respectively. The glucose infusion rate (GIR) was adjusted according to frequent measurements $(\sim 5$ min intervals) of blood glucose concentrations (ABL 625 , Radiometer, Copenhagen, Denmark).

\section{Western blotting analysis of muscle samples}

The procedure has previously been described in detail (Vigelsø et al. 2013). In brief, all biopsies were dissected free of visible adipose tissue, connective tissue, and blood. The biopsies were then homogenized in a buffer $(25 \mathrm{mM}$ Tris $\mathrm{pH}$ 6.8, $2 \mathrm{mM}$ sodium orthovanadate, $5 \mathrm{mM}$ EDTA, $20 \mathrm{mM}$ pyrophosphate, $3 \%$ SDS and $20 \mathrm{mM} \beta$-glycerophosphate) heated to $95^{\circ} \mathrm{C}$. Protein concentration was measured by the bicinchoninic acid (BCA) assay (Pierce, Rockford, IL USA). $20 \mu \mathrm{g}$ of protein was heated to $55{ }^{\circ} \mathrm{C}$ for $10 \mathrm{~min}$ and electrophoresed in $4-15 \%$ polyacrylamide sodium dodecyl sulphate gels (Bio-rad, Copenhagen, Denmark) and electro transferred to a PVDF membrane. Membranes were blocked for $1 \frac{1}{2} \mathrm{~h}$ at room temperature with either skimmed milk powder or bovine serum albumin (BSA) diluted in Tris-buffered saline and incubated with primary antibody overnight at $4{ }^{\circ} \mathrm{C}$. The primary antibodies were: Antibodies against mitochondrial subunit III-V (Total OXPHOS, ab110411, Abcam, Cambridge, UK), anti-insulin receptor subunit beta (sc-81465, Santa Cruz Biotechnology, Inc., Heidelberg, Germany), anti-Akt I (2967) \& II (2964), (Cell Signaling Technology, Beverly, MA, USA), anti-HK I (2024) \& II (2867) (Cell Signaling Technology), anti-glycogen synthase (ab40810, Abcam, Cambridge, UK), anti-GLUT4 (PA1-1065, Fischer Scientific, Roskilde, Denmark), anti-LIPG (EL, 071971E11, Sigma-Aldrich, Saint Louis, MO, USA), anti-LPL (sc-32885, Santa Cruz Biotechnology, Inc., Heidelberg, Germany), anti-ADRP (Perilipin 2, NB 110-4087, Novus Biologicals, Littleton, CO, USA), anti-TIP47 (Perilipin 3, R04251, Sigma, Prestige Antibodies, St. Louis, MO, USA), anti-OXPAT (Perilipin 5, NB110-60509, Novus Biologicals, Littleton, CO, USA), anti-ATGL (\#2138, Cell Signaling Technology) and anti-HSL (sc-74489, Santa Cruz Biotechnology, Inc.). Secondary antibodies were: polyclonal goat anti-rabbit horseradish peroxidase conjugated, (Dako, Glostrup, Denmark) and polyclonal goat anti-mouse horseradish peroxidase conjugated (Dako). The blots were developed in ECL detection reagents (Amersham, ECL Western Blotting Detection Reagents; GE Healthcare) and the chemiluminescence emitted from immune-complexes was visualized with an LAS 3000 image analyzer (FUJI FILM, Tokyo, Japan). The images were quantified by Multi Gauge software (FUJI FILM) and specific signals expressed as a percentage of an internal standard loaded (a pooled sample from all samples) in quadruple on each gel. The results are presented as relative to the average of the sedentary control group.

\section{Biochemical analysis of intramuscular triglycerides}

The intramuscular triglyceride content was biochemically determined as previously described (Folch et al. 1957, Kiens and Richter 1996). Muscle biopsies were carefully dissected free of excess lipids, connective tissue, and blood. Lipids were extracted using Folchs solution (chloroform $99.8 \%$, methanol $99.8 \%$ and water in a 1:1:1 ratio) and glycerol was measured photometrically. 


\section{Statistics}

All statistical analyses were performed in Sigma

Plot 12.5 (Systat software, Inc., San Jose, USA). Comparisons of group characteristics and protein expression were made using a Student's t-test. For correlations between different variables Pearson's product moment correlation coefficient $\left(\mathrm{R}^{2}\right)$ and corresponding $P$-value, were obtained. The level of significance was set at $P<0.05$. Data are expressed as mean \pm standard error of mean $( \pm$ SEM).

\section{Results}

\section{Study participants}

The characteristics of the participants, some have been published elsewhere (Skov-Jensen et al. 2007, Skovbro et al. 2008, Vigelsø et al. 2013), are given in Table 1. In brief, the TR had lower $(P<0.05)$ body mass index (BMI), weight, and whole body fat content compared with CON. TR had higher $(P<0.05)$ steady state glucose infusion rate $(\mathrm{ssGIR})\left(\mathrm{mg} \cdot[\mathrm{kg} \mathrm{LBM}]^{-1} \cdot \mathrm{min}^{-1}\right)$ and $\mathrm{VO}_{2} \max \left(\mathrm{ml} \mathrm{O}_{2} / \mathrm{min} / \mathrm{kg} \mathrm{LBM}\right)$ compared to $\mathrm{CON}$. Likewise, intramuscular glycogen content was higher $(P<0.05)$ in TR compared to CON (Table 1). Additionally, TR had higher $(P<0.05)$ plasma HDL concentration compared to $\mathrm{CON}(1.88 \pm 0.08$ vs. $1.40 \pm 0.07 \mathrm{mmol} \cdot \mathrm{l}^{-1}$ for $\mathrm{TR}$ and $\mathrm{CON}$, respectively) (Skov-Jensen et al. 2007). There was no difference in IMTG between the groups (Table 1).

\section{Protein levels}

The protein level of mitochondrial complex III and IV was app. $100 \%$ higher in TR compared to CON. Mitochondrial complex $\mathrm{V}$ expression was $60 \%$ greater in the TR than in CON (Fig. 1A).

\section{Glucose metabolism}

The insulin receptor subunit beta expression tended $(\mathrm{P}<0.08)$ to be higher in $\mathrm{TR}$ compared to $\mathrm{CON}$, whereas there was no difference in Akt I and Akt II expression (Fig. 1B).
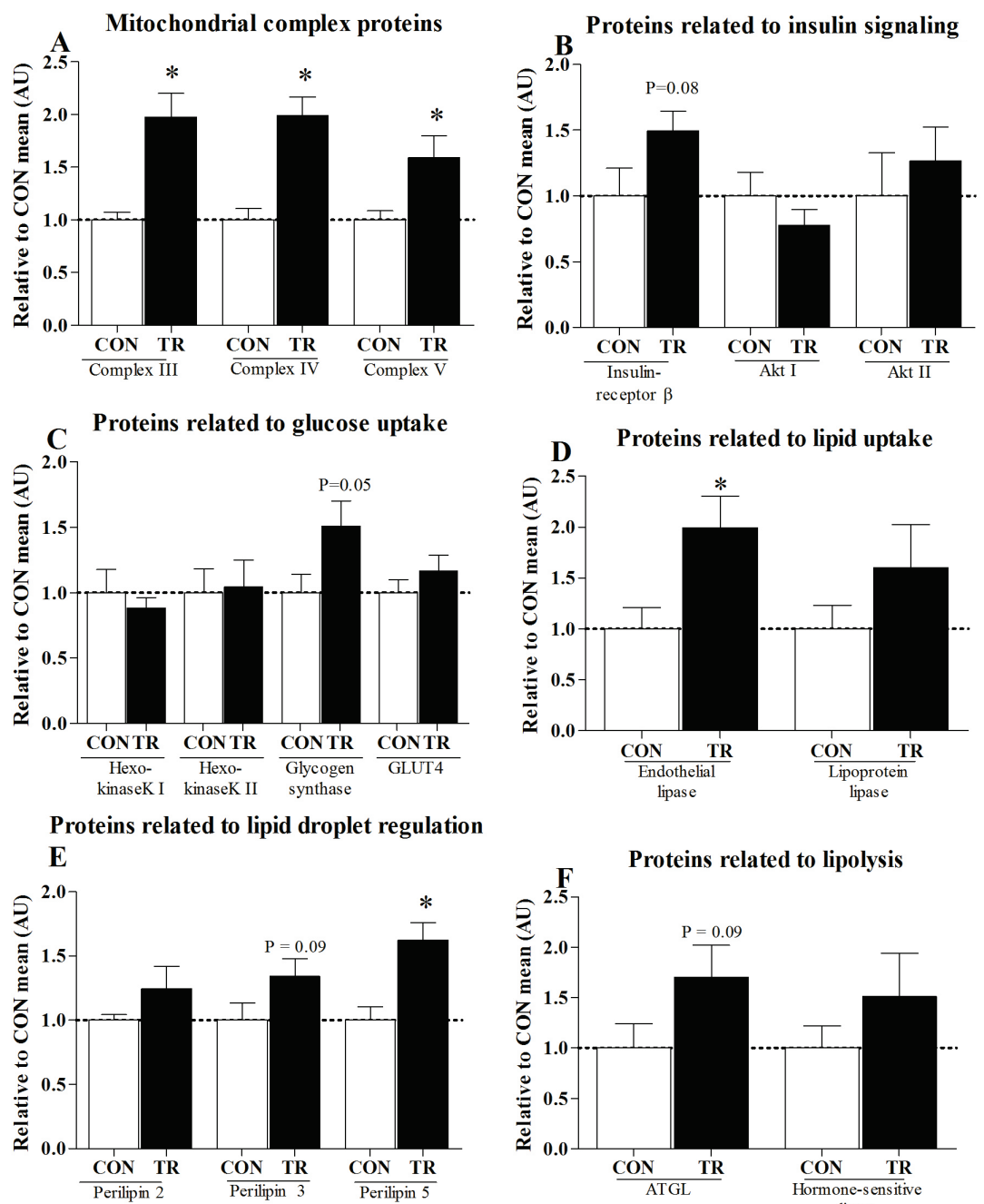

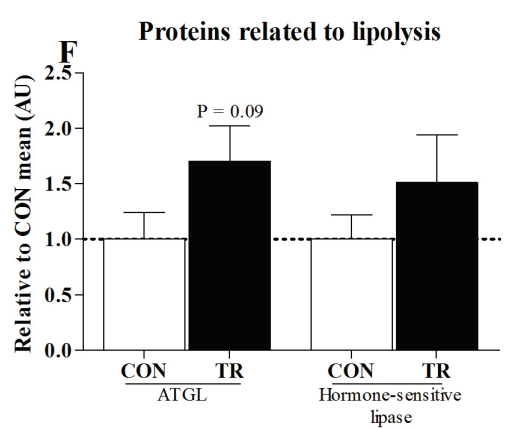

Fig. 1. Protein levels of important lipases in human skeletal muscle. A) mitochondrial complex III, IV and $\mathrm{V} ;$ B) insulin receptor subunit a, AKT I, and AKT II; C) hexokinase I, hexokinase II, glycogen synthase, and GLUT4; D) endothelial lipase and lipoprotein lipase; E) perilipin 2, 3 and 5; and F) adipose triglyceride lipase (ATGL), and hormone-sensitive lipase was determined by Western blotting in healthy sedentary controls (CON, $\mathrm{n}=8)$ and endurance trained men (TR, $\mathrm{n}=8$ ). The results are presented as means \pm SEM. The results are normalized against the means of the standard bands $(n=4)$, which is a pooled standard sample used for all Western blots in the study (STD). $20 \mu \mathrm{g}$ of muscle homogenate was loaded in all lanes. Representative blots are seen in Figure 3. 


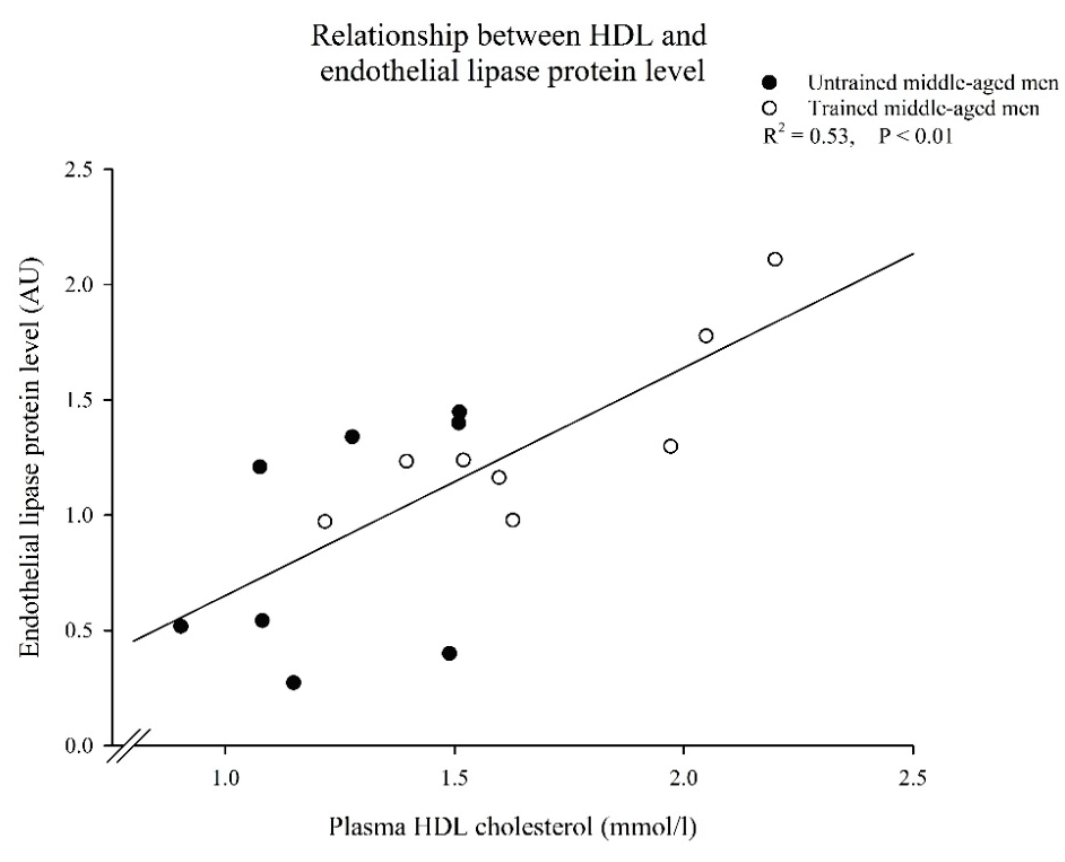

Fig. 2. Relationship between plasma HDL cholesterol and endothelial lipase protein level in endurance trained and untrained middle-age men. There was a significant positive correlation $\left(R^{2}=0.53, \quad P<0.01\right)$. When the correlation was tested separately for the two groups, significance was only observed for the trained group $\left(R^{2}=0.55, P<0.05\right)$, but not for the untrained group $\left(R^{2}=0.22, P=0.22\right)$, plots not shown.

The glycogen synthase expression tended $(\mathrm{P}=0.05)$ to be higher in TR compared to CON. However, there was no difference in hexokinase I, hexokinase II and GLUT4 protein levels between the groups (Fig. 1C).

\section{Lipid metabolism}

The EL expression was $100 \%$ higher $(P<0.05)$ in TR compared to CON, with no difference in the LPL protein level (Fig. 1D). For the lipid droplet proteins the perilipin 5 expression was $50 \%$ higher in TR compared to $\mathrm{CON}$ (Fig. 1E). In addition perilipin 3 expression tended to be higher $(P=0.09)$ in TR than CON, whereas perilipin 2 expression did not differ between the groups (Fig. 1E). The ATGL expression tended to be higher $70 \%(P=0.09)$ in TR compared to $\mathrm{CON}$ (Fig. 1F), whereas there was no difference in muscle HSL expression between groups (Fig. 1D). We observed a positive correlation between plasma HDL and protein expression of EL $\left(P<0.01, \mathrm{R}^{2}=0.53\right.$, Fig. 2$)$. Interestingly, a separate analysis within the two groups revealed that the correlation was mainly driven by $\mathrm{TR}\left(\mathrm{R}^{2}=0.55\right.$, $\mathrm{P}<0.05)$ and not $\mathrm{CON}\left(\mathrm{R}^{2}=0.22, \mathrm{P}=0.22\right)$ (Fig. 2).

\section{Representative Western blots}

For both glucose and lipid metabolism related proteins representative blots of the measured proteins are shown in Figure 3.

\section{Discussion}

The main finding is that a high whole-body
$\mathrm{VO}_{2} \mathrm{max}$, reflected in higher muscle mitochondrial complex expression, in middle-age is associated with higher muscle protein levels of endothelial lipase and perilipin 5 protein. Furthermore, we observed that plasma HDL concentration correlated positively with the endothelial lipase protein expression. In addition, muscle protein levels of perilipin 3, ATGL, insulin receptor subunit $\beta$, and glycogen synthase tended to be higher in the trained compared to the untrained middle-aged men. It is likely that these differences contribute to a higher metabolic flexibility and thus a lowered risk of developing metabolic diseases in the middle-aged trained compared to the untrained men.

\section{Glucose metabolism}

As expected based on the literature (Taylor et al. 1972), we observed higher muscle glycogen synthase expression consistent with the markedly higher muscle glycogen stores in the trained group. However, it was unexpected that there was no difference between the groups in hexokinase II (Frosig et al. 2007), AKT I and II (Frosig et al. 2007) and GLUT4 (Dela et al. 1993, Hickner et al. 1997, Ren et al. 1994), since these are normally, at least in young individuals, higher in trained compared to untrained individuals. The insulin sensitivity was as expected markedly higher in the trained compared to the untrained group, and it is thus possible that differences in intrinsic activity and/or in intracellular compartmentalization, possibly coupled to the aging process, rather than the protein level can explain this. 
A) Mitochondrial complex proteins

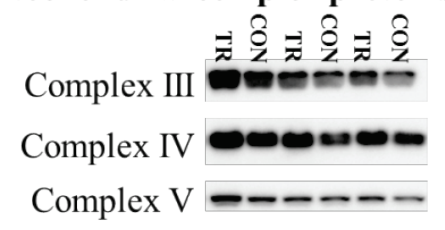

C) Glucose uptake

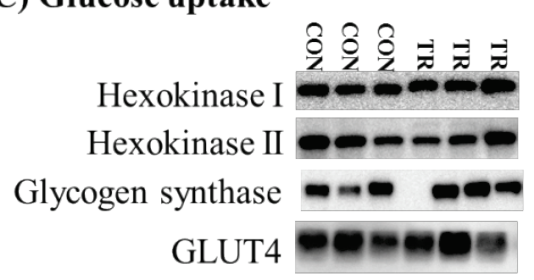

E) Lipid droplet regulation

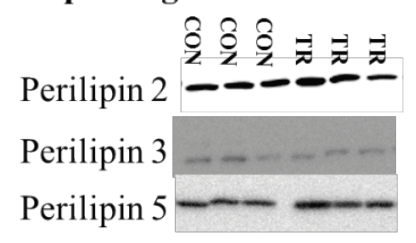

B) Insulin signaling

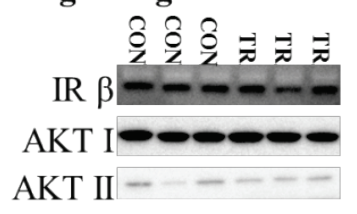

\section{D) Lipid uptake}

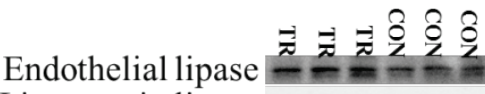

Lipoprotein lipase - - - -

F) Lipolysis

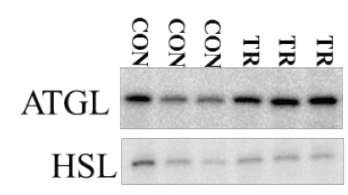

Fig. 3. Representative blots for data presented in Figure 1. A) mitochondrial complex III, IV and V; B) insulin receptor subunit a (IR $\beta)$, AKT I, and AKT II; C) hexokinase I, hexokinase II, glycogen synthase, and GLUT4; D) endothelial lipase and lipoprotein lipase; E) perilipin 2, 3 and 5; and F) adipose triglyceride lipase (ATGL), and hormone-sensitive lipase (HSL). TR: endurance trained middle-aged men. CON: untrained middle-aged men.

\section{Lipid metabolism}

We demonstrate that trained compared with untrained middle-aged men have greater protein expression of EL in the endothelium of skeletal muscle tissue. In a prior study we observed that EL expression was similar between untrained healthy middle aged men and age and lean body mass matched men with type 2 diabetes or impaired glucose tolerance (Vigelsø et al. 2013). Not much is known about the expression and function of endothelial lipase in human muscle tissue, but it is likely that a higher capillarization in the trained compared to the untrained muscle contributes to the higher expression in the endothelium of the trained muscle. Interestingly, we observed a positive correlation between plasma HDL and endothelial lipase protein level, which was mainly driven by a positive correlation in the trained but not the untrained group. This is in contrast to prior studies in mice with either whole-body knock out (Ishida et al. 2003, Ma et al. 2003) or global overexpression (Ishida et al. 2003, Jaye et al. 1999) of EL. These studies show an inverse relationship between plasma HDL and EL. There is no apparent explanation for this discrepancy, however, species difference, an artifact of the animal models (knock out and over expression) and/or divergent physiological roles for EL in the endothelium of e.g. the liver and adipose compared to muscle tissue may explain this. However, it is well known that regular training increases plasma HDLconcentration (Kiens et al. 1980, Nørregaard et al. 2015) and muscle capillarization (Coggan et al. 1992, Hepple et al. 1997) and this supports the observation of a positive correlation in the trained middle-aged men. Thus, it is possible that EL expression and plasma HDL are influenced by the same training induced mechanism. Although speculative, it is possible that EL could also contribute to FA uptake in skeletal muscle, as it has demonstrated for FA uptake in fat cells in mice (Kratky et al. 2005). Overall there is a need for further studies examining the expression and function of EL in human skeletal muscle.

We observed no difference in LPL protein expression, which was unexpected since LPL has been shown to increase with training in young individuals (Lithell et al. 1979, Nikkila et al. 1978, Taskinen and Nikkila 1980). However, in line with our observation, 6 months of endurance training in middle-aged men did not change muscle LPL mRNA levels (Smith et al. 2009). Further studies applying a longitudinal rather than a cross sectional design are needed to further elucidate the effects of training in middle-aged and older men on LPL.

The higher protein levels of perilipin 5 along with a similar trend for higher ATGL and perilipin 3 protein levels indicate that the trained middle-aged men have an improved lipid droplet regulation. The training induced increase in perilipin 5 expression in middle-aged men are in agreement with previously reported data in younger men (Bosma et al. 2012, Shepherd et al. 2013) 
and in older individuals (Amati et al. 2011). The trend toward higher ATGL and perilipin 3 after training is also in agreement with prior studies in young individuals (Alsted et al. 2009, Louche et al. 2013). Bosma and colleagues proposed that perilipin 5 is an important link between the lipid droplets and the mitochondria by showing increased lipid droplet interaction with mitochondria and higher rates of fatty acid oxidation with a 2-fold overexpression of perilipin 5 (Bosma et al. 2012). Therefore, perilipin 5 may be of particular importance in the regulation of tissue oxidative capacity (Bosma et al. 2012). Overall it seems that increased perilipin 5 expression in both middle-age as observed in this study, and in younger participants, is a consistent adaptation to endurance training.

Perilipin 2 protein expression was not affected by training in the present study, which is in line with previous findings in young men and women after 8-12 weeks aerobic training (Louche et al. 2013, Peters et al. 2012), but in contrast to another study (Shaw et al. 2012) also in young individuals. In the present study there was no difference in IMTG between the two groups (Table 1), which may indicate that perilipin 2 expression may be dependent on IMTG content rather than the training status. This notion is supported by a previously reported association between perilipin 2 and IMTG levels in some (measured by Oil Red O) (Shepherd et al. 2012, 2013, 2014), but not all (measured by electron microscopy) (Peters et al. 2012) studies. Overall, this highlights that the physiological expression and function of perilipin 2 needs further investigation, particularly since there may be some methodological limitations associated with the biochemical (Steffensen et al. 2002) and Oil Red O (Prats et al. 2013) analysis methods of IMTG.

Our observation of greater muscle mitochondrial complex II-V protein content is concurrent with the higher $\mathrm{VO}_{2} \mathrm{max}$ in middle-aged trained compared to untrained individuals and is consistent with a prior observation from our group (Gram et al. 2014).

\section{Limitations}

All the men in the trained group had performed endurance training consistently for many years, but they were not included based on a specific type of training but did various types of endurance training (mainly cycle training and running). Thus, although greater training status, differences in their training regimes, including intensity, duration, and exercise mode as well as their genetic makeup may have influenced their metabolic profile and muscle protein expression.

\section{Conclusion}

Our findings underline that having a high $\mathrm{VO}_{2} \mathrm{max}$ in middle-age has a favorable effect on key proteins involved in muscle metabolism. This was primarily muscle endothelium lipid metabolism (EL), lipid droplet regulation (perilipin 5) and GS. These adaptations may be favorable for maintaining a high metabolic flexibility, and thus may be important to counter the increased risk of developing metabolic diseases with age.

\section{Conflict of Interest}

There is no conflict of interest.

\section{Acknowledgements}

Financial support from The 1991 Pharmacy Foundation, NOVO Nordic Foundation, Direktør Verner Richter and Hustrus foundation, the foundation of 1870, Direktør Jacob and Olga Madsens foundation, Aase and Ejnar Danielsens foundation and EU project EXGENESIS 005272 is gratefully acknowledged. Furthermore, we thank Mette Skovbro², Camilla Skov-Jensen ${ }^{2}$, Thomas Beck $^{2}$, Jeppe Bach ${ }^{1}$, Gerda Hau ${ }^{2}$, and Regitze Kraunsøe ${ }^{1}$ from ${ }^{1}$ Center for Healthy Aging, ${ }^{2}$ Department of Biomedical Sciences, Faculty of Health Sciences, University of Copenhagen, Denmark, for providing excellent technical assistance.

\section{References}

ALSTED TJ, NYBO L, SCHWEIGER M, FLEDELIUS C, JACOBSEN P, ZIMMERMANN R, ZECHNER R, KIENS B: Adipose triglyceride lipase in human skeletal muscle is upregulated by exercise training. $\mathrm{Am} J$ Physiol Endocrinol Metab 296: E445-E453, 2009.

AMATI F, DUBE JJ, ALVAREZ-CARNERO E, EDREIRA MM, CHOMENTOWSKI P, COEN PM, SWITZER GE, BICKEL PE, STEFANOVIC-RACIC M, TOLEDO FG, GOODPASTER BH: Skeletal muscle triglycerides, diacylglycerols, and ceramides in insulin resistance: another paradox in endurance-trained athletes? Diabetes 60: 2588-2597, 2011. 
ANNEMA W, TIETGE UJ: Role of hepatic lipase and endothelial lipase in high-density lipoprotein-mediated reverse cholesterol transport. Curr Atheroscler Rep 13: 257-265, 2011.

BARTZ R, LI WH, VENABLES B, ZEHMER JK, ROTH MR, WELTI R, ANDERSON RG, LIU P, CHAPMAN KD: Lipidomics reveals that adiposomes store ether lipids and mediate phospholipid traffic. J Lipid Res 48: 837$847,2007$.

BONADONNA RC, GROOP LC, SIMONSON DC, DEFRONZO RA: Free fatty acid and glucose metabolism in human aging: evidence for operation of the Randle cycle. Am J Physiol 266: E501-E509, 1994.

BOSMA M, MINNAARD R, SPARKS LM, SCHAART G, LOSEN M, DE BAETS MH, DUIMEL H, KERSTEN S, BICKEL PE, SCHRAUWEN P, HESSELINK MK: The lipid droplet coat protein perilipin 5 also localizes to muscle mitochondria. Histochem Cell Biol 137: 205-216, 2012.

BRASAEMLE DL, DOLIOS G, SHAPIRO L, WANG R: Proteomic analysis of proteins associated with lipid droplets of basal and lipolytically stimulated 3T3-L1 adipocytes. J Biol Chem 279: 46835-46842, 2004.

COGGAN AR, SPINA RJ, KING DS, ROGERS MA, BROWN M, NEMETH PM, HOLLOSZY JO: Skeletal muscle adaptations to endurance training in 60- to 70-yr-old men and women. J Appl Physiol 72: 1780-1786, 1992.

COX JH, CORTRIGHT RN, DOHM GL, HOUMARD JA: Effect of aging on response to exercise training in humans: skeletal muscle GLUT-4 and insulin sensitivity J Appl Physiol 86: 2019-2025, 1999.

DELA F: On the influence of physical training on glucose homeostasis. Acta Physiol Scan 635: 1-41, 1996.

DELA F, HANDBERG A, MIKINES KJ, VINTEN J, GALBO H: GLUT 4 and insulin receptor binding and kinase activity in trained human muscle. $J$ Physiol Online 469: 615-624, 1993.

FOLCH J, LEES M, SLOANE STANLEY GH: A simple method for the isolation and purification of total lipides from animal tissues. J Biol Chem 226: 497-509, 1957.

FROSIG C, SAJAN MP, MAARBJERG SJ, BRANDT N, ROEPSTORFF C, WOJTASZEWSKI JF, KIENS B, FARESE RV, RICHTER EA: Exercise improves phosphatidylinositol-3,4,5-trisphosphate responsiveness of atypical protein kinase $\mathrm{C}$ and interacts with insulin signalling to peptide elongation in human skeletal muscle. J Physiol 582: 1289-1301, 2007.

GRAM M, VIGELSØ A, YOKOTA T, HANSEN CN, HELGE JW, HEY-MOGENSEN M, DELA F: Two weeks of one-leg immobilization decreases skeletal muscle respiratory capacity equally in young and elderly men. Exp Gerontol 58: 269-278, 2014.

GRIFFON N, BUDRECK EC, LONG CJ, BROEDL UC, MARCHADIER DH, GLICK JM, RADER DJ: Substrate specificity of lipoprotein lipase and endothelial lipase: studies of lid chimeras. J Lipid Res 47: 1803-1811, 2006.

HENRIKSSON J: Training induced adaptation of skeletal muscle and metabolism during submaximal exercise. J Physiol 270: 661-675, 1977.

HEPPLE RT, MACKINNON SL, GOODMAN JM, THOMAS SG, PLYLEY MJ: Resistance and aerobic training in older men: effects on VO2peak and the capillary supply to skeletal muscle. J Appl Physiol 82: 1305-1310, 1997.

HICKNER RC, FISHER JS, HANSEN PA, RACETTE SB, MIER CM, TURNER MJ, HOLLOSZY JO: Muscle glycogen accumulation after endurance exercise in trained and untrained individuals. J Appl Physiol 83: 897903, 1997.

HURLEY BF, NEMETH PM, MARTIN WH, HAGBERG JM, DALSKY GP, HOLLOSZY JO: Muscle triglyceride utilization during exercise: effect of training $J$ Appl Physiol 60: 562-567, 1986.

ISHIDA T, CHOI S, KUNDU RK, HIRATA K, RUBIN EM, COOPER AD, QUERTERMOUS T: Endothelial lipase is a major determinant of HDL level. J Clin Invest 111: 347-355, 2003.

JAYE M, LYNCH KJ, KRAWIEC J, MARCHADIER D, MAUGEAIS C, DOAN K, SOUTH V, AMIN D, PERRONE M, RADER DJ: A novel endothelial-derived lipase that modulates HDL metabolism. Nat Genet 21: 424-428, 1999.

KELLEY DE, MANDARINO LJ: Fuel selection in human skeletal muscle in insulin resistance: a reexamination. Diabetes 49: 677-683, 2000.

KELLEY DE, HE J, MENSHIKOVA EV, RITOV VB: Dysfunction of mitochondria in human skeletal muscle in type 2 diabetes. Diabetes 51: 2944-2950, 2002. 
KIENS B, RICHTER EA: Types of carbohydrate in an ordinary diet affect insulin action and muscle substrates in humans. Am J Clin Nutr 63: 47-53, 1996.

KIENS B, JORGENSEN I, LEWIS S, JENSEN G, LITHELL H, VESSBY B, HOE S, SCHNOHR P: Increased plasma HDL-cholesterol and apo A-1 in sedentary middle-aged men after physical conditioning. Eur J Clin Invest 10: 203-209, 1980.

KRATKY D, ZIMMERMANN R, WAGNER EM, STRAUSS JG, JIN W, KOSTNER GM, HAEMMERLE G, RADER DJ, ZECHNER R: Endothelial lipase provides an alternative pathway for FFA uptake in lipoprotein lipase-deficient mouse adipose tissue. J Clin Invest 115: 161-167, 2005.

LITHELL H, HELLSING K, LUNDQVIST G, MALMBERG P: Lipoprotein-lipase activity of human skeletal-muscle and adipose tissue after intensive physical exercise. Acta Physiol Scan 105: 312-315, 1979.

LOUCHE K, BADIN PM, MONTASTIER E, LAURENS C, BOURLIER V, DE GLISEZINSKI I, THALAMAS C, VIGUERIE N, LANGIN D, MORO C: Endurance exercise training up-regulates lipolytic proteins and reduces triglyceride content in skeletal muscle of obese subjects. J Clin Endocrinol Metab 98: 4863-4871, 2013.

MA K, CILINGIROGLU M, OTVOS JD, BALLANTYNE CM, MARIAN AJ, CHAN L: Endothelial lipase is a major genetic determinant for high-density lipoprotein concentration, structure, and metabolism. Proc Natl Acad Sci US A 100: 2748-2753, 2003.

MARTIN WH, DALSKY GP, HURLEY BF, MATTHEWS DE, BIER DM, HAGBERG JM, ROGERS MA, KING DS, HOLLOSZY JO: Effect of endurance training on plasma free fatty acid turnover and oxidation during exercise. Am J Physiol 265: E708-E714, 1993.

MCCOY MG, SUN GS, MARCHADIER D, MAUGEAIS C, GLICK JM, RADER DJ: Characterization of the lipolytic activity of endothelial lipase. J Lipid Res 43: 921-929, 2002.

NIKKILA EA, TASKINEN MR, REHUNEN S, HARKONEN M: Lipoprotein lipase activity in adipose tissue and skeletal muscle of runners: relation to serum lipoproteins. Metab Clin Exp 27: 1661-1667, 1978.

NØRREGAARD J, GRAM M, VIGELSØ A, WIUFF C, KUHLMAN AB, HELGE JW, DELA F: The effect of reduced physical activity and retraining on blood lipids and body composition in young and older adult men. $J$ Aging Phys Act 23: 489-495, 2015.

PETERS SJ, SAMJOO IA, DEVRIES MC, STEVIC I, ROBERTSHAW HA, TARNOPOLSKY MA: Perilipin family (PLIN) proteins in human skeletal muscle: the effect of sex, obesity, and endurance training. Appl Physiol Nutr Metab 37: 724-735, 2012.

PRATS C, GOMEZ-CABELLO A, NORDBY P, ANDERSEN JL, HELGE JW, DELA F, BABA O, PLOUG T: An optimized histochemical method to assess skeletal muscle glycogen and lipid stores reveals two metabolically distinct populations of type I muscle fibers. PloS One 8: e77774, 2013.

REN JM, SEMENKOVICH CF, GULVE EA, GAO J, HOLLOSZY JO: Exercise induces rapid increases in GLUT4 expression, glucose transport capacity, and insulin-stimulated glycogen storage in muscle. J Biol Chem 269: 14396-14401, 1994.

RITZ P, ACHESON KJ, GACHON P, VICO L, BERNARD JJ, ALEXANDRE C, BEAUFRERE B: Energy and substrate metabolism during a 42-day bed-rest in a head-down tilt position in humans. Eur J Appl Physiol Occup Physiol 78: 308-314, 1998.

SHAW CS, SHEPHERD SO, WAGENMAKERS AJ, HANSEN D, DENDALE P, VAN LOON LJ: Prolonged exercise training increases intramuscular lipid content and perilipin 2 expression in type I muscle fibers of patients with type 2 diabetes. Am J Physiol Endocrinol Metab 303: E1158-E1165, 2012.

SHEPHERD SO, COCKS M, TIPTON KD, RANASINGHE AM, BARKER TA, BURNISTON JG, WAGENMAKERS AJ, SHAW CS: Preferential utilization of perilipin 2-associated intramuscular triglycerides during $1 \mathrm{~h}$ of moderate-intensity endurance-type exercise. Exp Physiol 97: 970-980, 2012.

SHEPHERD SO, COCKS M, TIPTON KD, RANASINGHE AM, BARKER TA, BURNISTON JG, WAGENMAKERS AJ, SHAW CS: Sprint interval and traditional endurance training increase net intramuscular triglyceride breakdown and expression of perilipin 2 and 5. J Physiol 591: 657-675, 2013.

SHEPHERD SO, COCKS M, TIPTON KD, WITARD OC, RANASINGHE AM, BARKER TA, WAGENMAKERS AJ, SHAW CS: Resistance training increases skeletal muscle oxidative capacity and net intramuscular triglyceride breakdown in type I and II fibres of sedentary males. Exp Physiol 99: 894-908, 2014. 
SKOV-JENSEN C, SKOVBRO M, FLINT A, HELGE JW, DELA F: Contraction-mediated glucose uptake is increased in men with impaired glucose tolerance. Appl Physiol Nutr Metab 32: 115-124, 2007.

SKOVBRO M, BARANOWSKI M, SKOV-JENSEN C, FLINT A, DELA F, GORSKI J, HELGE JW: Human skeletal muscle ceramide content is not a major factor in muscle insulin sensitivity. Diabetologia 51: 1253-1260, 2008.

SMITH IJ, HUFFMAN KM, DURHEIM MT, DUSCHA BD, KRAUS WE: Sex-specific alterations in mRNA level of key lipid metabolism enzymes in skeletal muscle of overweight and obese subjects following endurance exercise. Physiol Genomics 36: 149-157, 2009.

STEFFENSEN CH, ROEPSTORFF C, MADSEN M, KIENS B: Myocellular triacylglycerol breakdown in females but not in males during exercise. Am J Physiol Endocrinol Metab 282: E634-E642, 2002.

STORLIEN L, OAKES ND, KELLEY DE: Metabolic flexibility. Proc Nutr Soc 63: 363-368, 2004.

TASKINEN MR, NIKKILA EA: Effect of acute vigorous exercise on lipoprotein lipase activity of adipose tissue and skeletal muscle in physically active men. Artery 6: 471-483, 1980.

TAYLOR AW, THAYER R, RAO S: Human skeletal muscle glycogen synthetase activities with exercise and training. Can J Physiol Pharmacol 50: 411-415, 1972.

TONINO RP: Effect of physical training on the insulin resistance of aging. Am J Physiol 256: E352-E356, 1989.

VIGELSØ A, PRATS C, PLOUG T, DELA F, HELGE JW: Human skeletal muscle perilipin 2 and 3 expression varies with insulin sensitivity. J Biomed Sci Eng 6: 65-72, 2013. 